\title{
Effect of Strain Rate on Reinforced Concrete Columns
}

\author{
Debin Wang1, a, Guoxi Fan ${ }^{2, b^{*}}$ \\ ${ }^{1}$ School of Civil and Safety Engineering, Dalian Jiaotong University, Dalian, Liaoning, China \\ ${ }^{2}$ School of Engineering, Ocean University of China, Qingdao, Shandong, China \\ bfanguoxi-6688@163.com
}

Keywords: reinforced concrete column, strain rate, Timoshenko beam theory, dynamic loading Abstract. In order to study the effect of strain rate on reinforced concrete columns under earthquake action, two group reinforced concrete columns with constant axial load were subjected to cyclic uniaxial and biaxial tests with different loading rates. The experimental program is described. Then, tests results about reinforced concrete columns dynamic behavior are presented and discussed under uniaxial or biaxial tests. Based on the fiber model theory and Timoshenko beam theory, considering the strain rate sensitivity of steel and concrete, a new three-dimensional beam element is proposed. According to the calculation model of reinforced concrete columns mentioned above, the dynamic performances of reinforced concrete columns are simulated which show a good agreement with the test results.

\section{Introduction}

In reinforced concrete building structures, almost all reinforced concrete members will inevitably encounter dynamic action during their design lifetime. It has been found that the mechanical behavior of reinforced concrete members under dynamic loading is different from that under static loading. However, study on the mechanical behavior of reinforced concrete members under dynamic loading tests is few described in the existing literature[1,2,3,4,5].

Compared with experimental investigation, the finite element analysis is one of the effective methods to study the dynamic properties of structural members. Adhikary et al.[6] established three-dimensional nonlinear finite element model by LS-DYNA, and analyzed the mechanical behavior of reinforced concrete beams. Sharma et al.[7] carried out numerical studies on reinforced concrete beams, and analyzed the effect of loading rate on the failure modes of different specimens under various shear span ratios using a 3D finite element code (MASA).

In this paper, two group specimens are tested to investigate the influence of loading rate on the dynamic properties of reinforced concrete columns. In addition, according to the fiber model and Timoshenko beam theory, a three-dimensional beam element that can reflect the effect of strain rate of concrete and steel is built in the paper. The three-dimensional beam element can analyze the dynamic mechanical properties of reinforced concrete columns.

\section{Experimental Program}

\section{Specimens, Testing set-up and Loading scheme}

In this paper, two series of reinforced concrete columns were constructed with the same reinforcements and geometric characteristics. And cyclic tests with different loading scheme were carried out. The dimensions and reinforcement detailing of reinforced concrete columns are shown in Figure 1. All the specimens have the same extent of stirrup reinforcements and longitudinal reinforcements with a concrete cover of $15 \mathrm{~mm}$. The strength of stirrup reinforcement and longitudinal reinforcement are $414.3 \mathrm{Mpa}$ and $343.4 \mathrm{Mpa}$, respectively. The shear span ratio, longitudinal reinforcement ratio and axial compression ratio for all specimens are 4.3, 2.26\% and 0.095, respectively. And the compressive strength of concrete is $26.24 \mathrm{Mpa}$. The detailed introduction of testing set-up is shown in Reference[5]. 


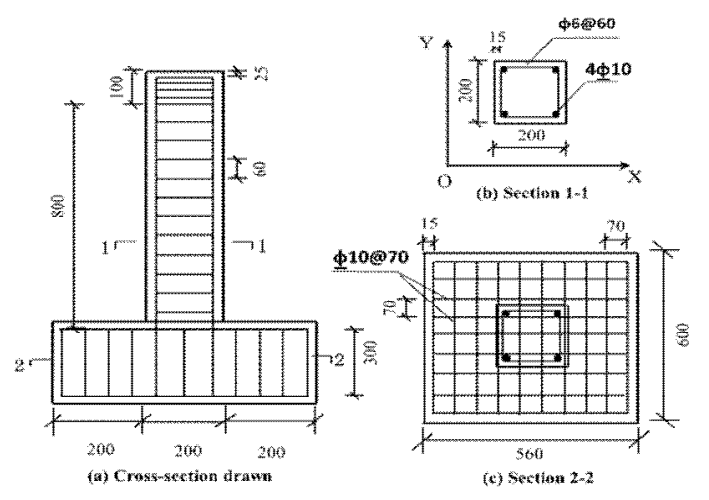

Figure.1 Dimensions of test specimens

The main purpose of this paper is to study the mechanical properties of RC columns under uniaxial or biaxial horizontal cyclic loadings with different loading rate. Two specimens were tested under uniaxial loading with loading rate of $0.1 \mathrm{~mm} / \mathrm{s}$ and other specimens were tested under biaxial loading with loading rate of $60 \mathrm{~mm} / \mathrm{s}$. It should be noted that all specimens were tested with constant axial force and displacement control loading. Two series of specimens included D-RC1, S-RC1,D-RC2, S-RC2. For specimen label, the character $\mathrm{D}$ and $\mathrm{S}$ represent the loading rate of $60 \mathrm{~mm} / \mathrm{s}$ and $0.1 \mathrm{~mm} / \mathrm{s}$, respectively. The adopted load scheme is summarized in Table 1 and the following nominal peak displacement level (mm) were considered: 5, 10, 15, 20, 25, 30, 35, 40, 45, 50.

Table.1 Loading Scheme

\begin{tabular}{c|cccc}
\hline Specimens & D-RC1 & S-RC1 & D-RC2 & S-RC2 \\
\hline Loading scheme & $\uparrow$ & & & \\
\hline $\begin{array}{c}\text { Loading rate } \\
{[\mathrm{mm} / \mathrm{s}]}\end{array}$ & 60 & & & \\
\hline
\end{tabular}

\section{Test results}

The load-displacement curves obtained from the cyclic tests are shown in Figure 2. From the analysis of the hysteresis curves, remarkable differences between the reloading stiffness and unloading stiffness can be found in the uniaxial and biaxial loading test. Under biaxial loading, the interaction of biaxial deformation apparently weakens the bearing capacity of the reinforced concrete column, and the plastic deformation ability of the specimen decreases under biaxial loading.
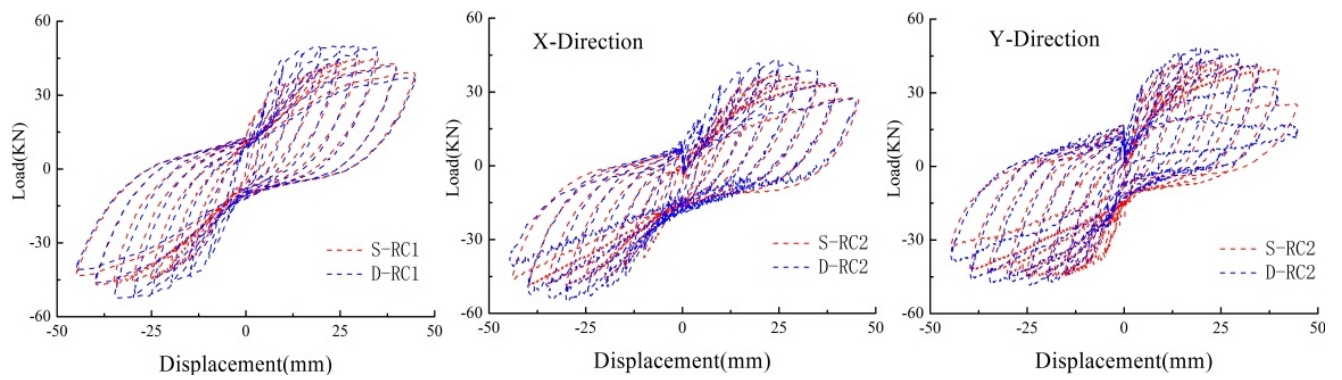

Figure.2 Load-displacement curves

At the same time, the bearing capacity of the reinforced concrete column is enhanced under the loading rate of $60 \mathrm{~mm} / \mathrm{s}$ due to bond-slip effect and strain rate sensitivity of concrete and steel. Both bearing capacity and stiffness degradation of the reinforced concrete column subjected to loading rate 
of $60 \mathrm{~mm} / \mathrm{s}$ are significantly higher that subjected to loading rate of $0.1 \mathrm{~mm} / \mathrm{s}$. The deformation capacity of the reinforced concrete column is decreased with the increasing of loading rate, especially for the biaxial loading test.

\section{Numerical Simulation}

\section{Fiber beam element of reinforced concrete columns}

Based on Timoshenko beam theory and fiber model theory, considering the strain rate effect of materials and shear effect, a three-dimensional beam element of the reinforced concrete member is established in order to simulate the mechanical properties of reinforced concrete columns under dynamic loading tests.

The main assumptions of three-dimensional beam element model are shown as follows.

1) Cross sections remain plane;

2) The constitutive of fibers are one-dimensional dynamic constitutive function of materials

3) The torsion deformation and non-linear geometry are not concerned.

The element node force vector and displacement vector are shown as follows.

$$
\begin{aligned}
& F^{e}=\left[\begin{array}{llllllllll}
F_{x 1} & F_{y 1} & F_{z 1} & M_{y 1} & M_{z 1} & F_{x 2} & F_{y 2} & F_{z 2} & M_{y 2} & M_{z 2}
\end{array}\right]^{T} . \\
& d^{e}=\left[\begin{array}{llllllllll}
u_{1} & v_{1} & w_{1} & \phi_{1} & \varphi_{1} & u_{2} & v_{2} & w_{2} & \phi_{2} & \varphi_{2}
\end{array}\right]^{T} .
\end{aligned}
$$

The section internal force vector is shown as follows.

$$
\Delta F^{s}=\left[\begin{array}{lllll}
\Delta N & \Delta Q_{y} & \Delta Q_{z} & \Delta M_{y} & \Delta M_{z}
\end{array}\right]^{T}=D \cdot \Delta d^{s} .
$$

The section tangent stiffness matrix $\mathrm{D}$ is

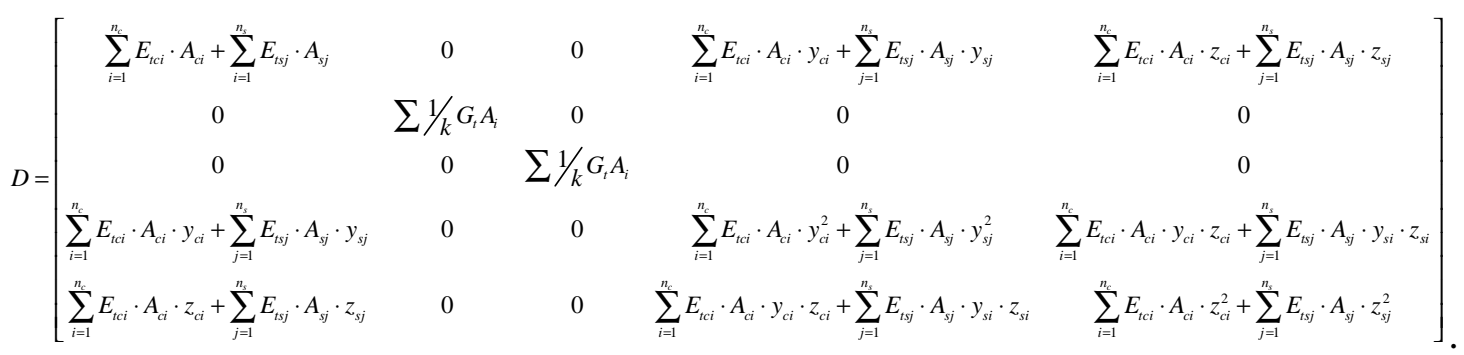

Based on the principle of virtual work at small deformation, the stiffness function of element in the incremental form is shown as

$$
\Delta P^{e}=K^{e} \cdot \Delta d^{e} .
$$

The element stiffness matrix $K^{e}$ and element node force $\Delta P^{e}$ are expressed as

$$
\begin{aligned}
& K^{e}=\int_{0}^{L} B^{T} D B d x . \\
& \Delta P^{e}=\int_{0}^{L} B^{T} \Delta F^{s} d x .
\end{aligned}
$$




\section{Dynamic constitutive behavior}

Rate-dependent constitutive model of concrete: The concrete dynamic constitutive model only introduces compressive skeleton curves and hysteretic rulers. The Soroushian model of concrete is taken for this calculation. The detailed introduction of the concrete constitutive model is shown in Reference [7].

Rate-dependent constitutive model of steel: Ideal elastic-plastic model is used as the calculation model in this paper. The relationship of dynamic yield strength and quasi-static yield strength of steel is shown as follows[8].

$$
\frac{f_{y d}}{f_{y s}}=1+0.0643 \lg \frac{8 \&}{8 \&} \text {. }
$$

Dynamic shear modulus $\mathrm{G}_{\mathrm{td}}$ : The dynamic shear modulus $\mathrm{G}_{\mathrm{td}}$ of confined concrete[9] is defined as

$$
G_{t d}=\frac{\tau_{p d}}{\gamma_{p d}}\left[1.9-5.1\left(\frac{\gamma}{\gamma_{p d}}\right)^{2}+3.2\left(\frac{\gamma}{\gamma_{p d}}\right)^{3}\right] .
$$

\section{Simulation results}

The calculation model of reinforced concrete columns is established by introducing the constitutive model of materials and three-dimensional beam element mentioned above in Feappv which is a finite element analysis program. Based on the calculation model of reinforced concrete columns, the tests results of static and dynamic cyclic loading are simulated in this paper.
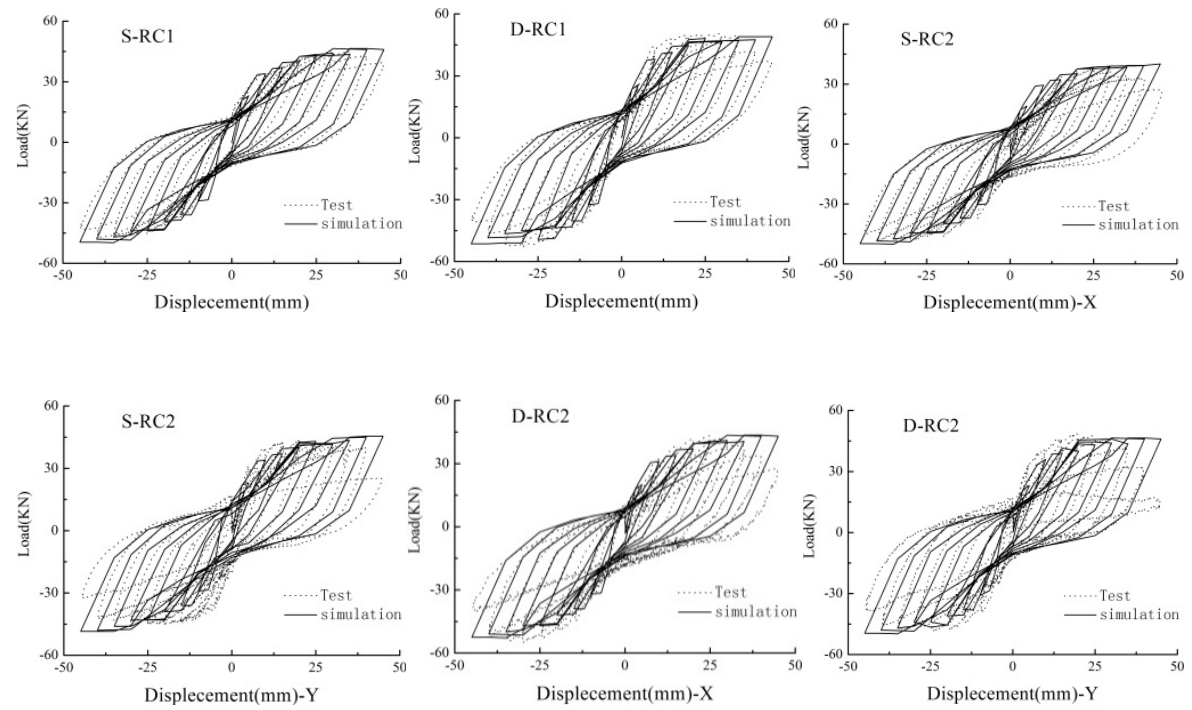

Figure.3 Simulated results

The load-displacement curves of the column at different loading rate are shown in Figure 3. As shown in Figure 3, the simulation curves agree well with the experimental curves in the whole loading process.

\section{Conclusions}

Based on the above analysis, the following inclusions are summarized as: 
1)The bearing capacity of reinforced concrete columns are enhanced under fast loading rate due to strain rate effect of materials;

2)Under biaxial loading, the interaction of biaxial deformation apparently weaken the bearing capacity of reinforced concrete columns, and the plastic deformation ability of the specimen decreases under biaxial loading.

3)The mechanical behavior of reinforced concrete columns with different loading rates is simulated by the three-dimensional beam element mentioned above and the simulation results agreed well with the test results.

\section{Acknowledgements}

The authors would like to thank the National Natural Science Foundation of China (Grant No. 51408093; No. 51308085); the Scientific Research Project of Education Bureau of Liaoning Province, China (Grant No. L2015098); the Fundamental Research Fund for Dalian Jiaotong University (Grant No. 888160); the Key Project of State Key Laboratory of Coastal and Offshore Engineering for Dalian University of Technology (Grant No. LP1617); Postdoctoral Application Research Program of Qingdao City (Grant No. 861605040024).

\section{References}

[1] T. Zhan, Z. Wang and J. Ning. Engineering Failure Analysis (2015)

[2] S.D. Adhikary, B. Li and K. Fujikake. International Journal of Impact Engineering (2012)

[3]G.X. Fan, Y.P. Song. Magazine of Concrete Research (2014)

[4] S. Xiao, W. Cao, H. Pan. Journal of Building Structures (2012)

[5] D.B. Wang, H.N. Li and G. Li. Construction and Building Materials (2013)

[6] S.D. Adhikary, B. Li and K. Fujikake. Nuclear Engineering and Design (2013)

[7] P. Soroushian, K.B. Choi and A. Alhamad. Journal Proceedings. Vol. 83(1986), p. 251-259.

[8] M. Li, H.N. Li. China Civil Engineering Journal (2010) (in Chinese).

[9] A. Suzuki, J. Mizuno, I. Matsuo, et al. WIT Transactions on The Built Environment (1999) 